\title{
Corrosion Monitoring of Sabic Iron in Hydrochloric Acid Solutions using some Azo Compounds - Molecular Dynamics, Chemical and Electrochemical Studies
}

\author{
H. Shokry, ${ }^{\star a, b}$ R. Shah ${ }^{\mathrm{a}}$ and E. M. Mabrouk ${ }^{\mathrm{a}}$ \\ ${ }^{a}$ Chemistry Department, Faculty of Applied Science, Umm-AI Qura University, Makah, Saudi Arabia \\ ${ }^{\mathrm{b}}$ Chemistry Department, Faculty of Science, Kafr El-Sheikh University, Kafr El-Sheikh 33516, Egypt \\ 1st author's E-mail: drheshokry@yahoo.com \\ 2nd E-mail: Reem.shah@hotmail.com \\ 3rd E-mail: drsayedmabrouk@yahoo.com
}

\section{ABSTRACT}

\begin{abstract}
The corrosion inhibition behaviour of Sabic iron in the absence and in presence of some azo compounds derived from 2 , 3-and 2, 7-dihydroxynaphthalene was investigated using weight loss, thermometry and galvanostatic polarizations techniques. It was found that, the inhibition efficiency of these compounds depends on their concentration and chemical structure. The inhibitive action of these azo compounds was discussed in terms of blocking the electrode surface by adsorption of the azo dye molecules through the active centres in their structure. The adsorption process follows Temkin isotherm. The effect of temperature on the rate of corrosion was considered and some activated thermodynamic functions were computed and discussed. Quantum chemical calculations and molecular simulations were further applied to reveal the adsorption structure and explain the experimental results.
\end{abstract}

\section{Indexing terms/Keywords}

Iron; Corrosion; Inhibitors; Naphthalene azo dyes; Adsorption; Quantum chemical calculations.

\section{Academic Discipline And Sub-Disciplines}

Physical chemistry

\section{SUBJECT CLASSIFICATION}

Corrosion

\section{TYPE (METHOD/APPROACH)}

Experimental study and Molecular Simulation.

\section{Council for Innovative Research}

Journal: Journal of Advances in Chemistry

Peer Review Research Publishing System

Vol. 5, No. 2

editor@cirworld.com

www.cirworld.com, member.cirworld.com 


\section{INTRODUCTION}

Corrosion inhibitors widely used to reduce the corrosion rate of metals and alloys which are present in contact with aggressive environments. Industrial applications like acid pickling, acid cleaning of boilers, descaling and oil well acidizing utilize several of acidic solutions [1] and to prevent base metal attack during these processes, corrosion inhibitors are widely employed. The selection of appropriate inhibitors mainly depends on the type of acid, its concentration, temperature, velocity, presence of dissolved solids and the type of metallic materials involved.

The most of efficient inhibitors are organic compounds having $\pi$ bonds in their structures [2, 3]. The efficiency of an organic compound as a successful inhibitor is mainly dependent on its ability to get adsorbed on the metal surface. The process of adsorption is influenced by the metal surface, the chemical structure of the organic inhibitor, the distribution of charge in the molecule, the type of aggressive electrolyte and the type of interaction between organic molecules and the metallic surface [4].

Iron is considered to be one of the most important metals which are frequently used in different industrial applications therefore, the inhibition of iron corrosion was the subject of several studies [5-13]. Results showed that organic compounds, especially those containing nitrogen, sulphur and oxygen atoms gave very good inhibition effect for iron in acidic solutions. However, it remains an important objective to find more efficient low-cost organic inhibitors.

Inhibition of carbon steel corrosion by some thiophene azo dyes in $2 \mathrm{M} \mathrm{HCl}$ was investigated [14]. The purines and its derivatives, such as, guanine, adenine, 2, 6-diaminopurine, 6-thioguanine and 2, 6-dithiopurine, were investigated as corrosion inhibitors for mild steel in $1 \mathrm{M} \mathrm{HCl}$ solution [15]. The corrosion inhibition and adsorption process of 1,2 diaminoanthraquinone (DAQ) on mild steel in $\mathrm{HCl}$ was studied at different temperatures $(303-333 \mathrm{~K})$ [16].

Corrosion protection of mild steel in $0.5 \mathrm{M} \mathrm{H}_{2} \mathrm{SO}_{4}$ solution was studied using combination of benzene-1, 2-diamine and benzaldehyde with $\mathrm{FeCl}_{3}$ to in situ synthesis of new inhibitor at different temperatures employing electrochemical, weight loss, quantum chemical studies and optical microscopy [17].

The density functional theory (DFT) at the B3LYP/631G (d) basis set level was performed on three phenanthroline derivatives used as corrosion inhibitors, namely 2 -mesityl-1H-imidazo $[1,4,5,10]$ phenanthroline $(\mathrm{G}), 2$ - $(6$-methylpyridin2-yl)-1 H-imidazo [1, 4, 5, 10] phenanthroline (J) and 2-(pyridine-2-yl)-1H-imidazo $[1,4,5,10,18]$ phenanthroline (K) to investigate the correlation between molecular structure and the corresponding inhibition efficiency $(1 \%)$ [19].

The aim of the present study is to investigate the ability of some azo dye compounds derived from dihydroxynaphthalene to inhibit the corrosion of Sabic iron in hydrochloric acid solutions using weight loss, thermometry and polarization techniques, it was also the purpose of the present work to test the experimental data with several adsorption isotherms at different temperatures, in order to determine the standard free energies of the adsorption process and gain more information on the mode of adsorption of the inhibitor on the electrode surface. In order to investigate the relationship between inhibition efficiency and the structure of studied azo dye compounds, some quantum chemical parameters such as HOMO and LUMO energies, charge density of adsorption centres and dipole moment have also been calculated. The local reactivity is analyzed through the Fukui function and condensed softness indices in order to compare the possible sites for nucleophilic and electrophilic attacks.

\section{EXPERIMENTAL}

\section{Synthesis of the azo dye compounds}

The studied monoazo dye compounds were prepared by coupling the diazoniun salt of aromatic amine; o-ansidine and anthranilic acid with 0.01 mole of 2, 3- and 2, 7-dihydroxynaphthalenes as described elsewhere [20]. The prepared azo dyes were characterised by elemental analysis, IR and ${ }^{1} \mathrm{Hnmr}$ spectra. The test compounds have the following structural formula:

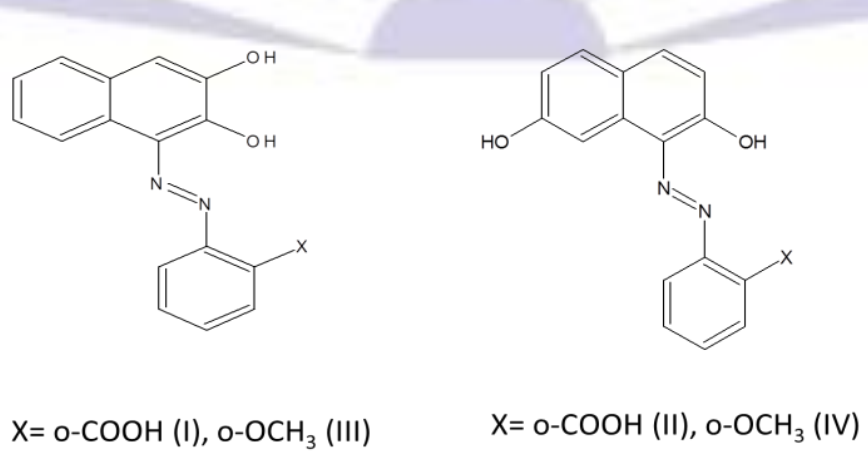

Fig. 1 Molecular structure of investigated azo dye compounds (I-IV).

\section{Materials and measurements}

The materials used in this study were made of pure iron obtained from Saudi Iron and Steel Company (Sabic) having the following chemical composition: (\%) C, 0.052; Mn, 0.189; S, 0.011; Al, 0.039; N, 0.001; Cr, 0.0128; Cu, 0.04; Mo, 0.024; 
$\mathrm{Ni}, 0.0239$ and the remainder is Fe. In all measurements and to prior to each experiment, the surface of iron specimens were mechanically polished with 1-, 0 -, 00 - emery paper, degreased with acetone, rinsed by distilled water and finally dried between two filter papers.

For weight loss measurements, the cleaned iron sheets of area $2 \mathrm{~cm}^{2}$ was weighed before and after immersion in 50 $\mathrm{ml}$ of the test solution for a period of time (30 minutes) at room temperature. The average weight loss $(W)$ for each two identical experiments was taken and expressed in $\mathrm{mg}$. The corrosion rate $\left(R_{\text {corr }}\right)$ was calculated using the following equation [21]:

$$
R_{\text {corr }}=W(\mathrm{mg}) / A\left(\mathrm{dm}^{2}\right) \times t \text { (day) }
$$

where $A$ is the area of the specimen in $\mathrm{dm}^{2}$ and $t$ is the period of immersion in day.

The percentage inhibition efficiency (IE\%) of the test azo dyes was calculated using the equation:

$$
I E \%=\left(1-W_{\text {add }} / W_{\text {free }}\right) \times 100
$$

where $W_{\text {free }}$ and $W_{\text {add }}$ are the weight of the metal sheet in absence and in presence of the inhibitor, respectively.

The degree of surface coverage $(\theta)$ which represents the part of metal surface covered by inhibitor molecules was calculated using the equation [22]:

$$
\theta=1-W_{\text {add }} / W_{\text {free }}
$$

In thermometric measurements, the procedure has been described by Mylius [23] in which the iron specimen was immersed in the test solution. The initial temperature $\left(T_{i}\right)$ in all experiment was measured and the progress of the corrosion reaction was monitored by determining the change in temperature with time using a calibrated thermometer. The corrosion rate was calculated using the equation:

$$
R N=\left(T_{\mathrm{m}}-T_{\mathrm{i}}\right) / t
$$

where $R N$ is the reaction number, $T_{\mathrm{m}}$ is the maximum temperature, $T_{\mathrm{i}}$ is the initial temperature and $\mathrm{t}$ is the time in minutes at maximum temp.

The percentage inhibition efficiency (IE\%) of the test azo dyes was calculated using the equation:

$$
I E \%=\left[\left(R N_{\text {free }}-R N_{\text {add }}\right) / R N_{\text {free }}\right] \times 100
$$

where $R N_{\text {free }}$ and $R N_{\text {add }}$ are the reaction number in absence and in presence of the inhibitor, repectively.

For galvanostatic polarization, measurements were carried out using an EG\&G model 173 Potentiostat/Galvanostat. The electrode potential was measured against a saturated calomel electrode (SCE). A platinum foil was used as an auxiliary electrode. The percentage inhibition efficiency $(I E \%)$ of the used inhibitors was calculated using the following equation:

$$
I E \%=\left(1-I_{\text {add }} / I_{\text {free }}\right) \times 100
$$

where $I_{\text {free }}$ and $I_{\text {add }}$ are the corrosion current densities in absence and in presence of the inhibitor, respectively.

\section{Theoretical calculation}

For quantum chemical calculations, the study was carried out using ab initio with basis set STO-3G method with commercially available quantum chemical software HyperChem, Release 8.0 [24]. A full optimization of all geometrical variables without any symmetry constraint was performed at the Restricted Hartree-Fock (RHF) level [25, 26]. This develops the molecular orbitals on a valence basis set and also, calculates electronic properties, optimized geometries and total energy of the molecules. As an optimization procedure, the built-in Polak-Ribiere algorithm was used [27].

\section{RESULTS AND DISCUSSION}

\section{Weight loss measurements}

Table (1) shows the values of corrosion rate $\left(R_{\text {corr }}\right)$, inhibition efficiency $(I E)$ and the surface coverage $(\theta)$ obtained from weight loss measurements of iron electrode in $2 \mathrm{M}$ hydrochloric acid solutions in absence and in presence of the tested azo dye compounds (I-IV). Inspection of Table (1) reveals that the corrosion rate decreases and the inhibition efficiency increases with increasing the inhibitor concentration within the range $1 \times 10^{-4}, 1 \times 10^{-6} \mathrm{M}$. This behaviour could be attributed to the increase of the surface coverage $(\theta)$ as the inhibitor concentration is increased. However, the values of inhibition efficiency given in Table (1) indicated that naphthalene azo compounds (I-IV) exhibited a very good performance on the corrosion of iron in $2 \mathrm{M} \mathrm{HCl}$ solutions. The inhibition achieved by these compounds increases from azo dye compound IV to azo dye compound $\mathrm{I}$. 


\section{Thermometric measurements}

Effect of concentration of azo dye compound (I) on the thermometric curves of iron in $2 \mathrm{M} \mathrm{HCl}$ solutions was investigated and represented in Fig. 2 as an example. However, similar curves (not shown) were obtained for the other compounds. The thermometric curves revealed that the dissolution of iron in $\mathrm{HCl}$ solutions is characterised by an initial slow rise of temperature followed by a sharp rise and finally a decrease after attaining a maximum value. As the concentration of the additives increases, the time required to reach the maximum temperature $\left(T_{\mathrm{m}}\right)$ increases and consequently, the rate of temperature rise decreases. The reaction number $(R N)$ of the test azo dye was measured and the extent of corrosion inhibition by a certain concentration of the additives is evaluated from the percentage reduction number $(R R N \%)$ which represents the inhibition efficiency (IE). The results obtained Table (2) denoted that the $R N$ decreases and consequently, the $R R N \%$ increase on increasing the concentration of the additives, i. e, the IE increases in the same order of the weight loss results.

It is of interest to mention that the results of thermometric method are in agreement with those obtained from weight loss measurements.

\section{Galvanostatic Polarization measurements}

Galvanostatic polarization of iron was studied in $0.1 \mathrm{M}$ hydrochloric acid solutions in absence and in presence of inhibitors (I-IV). Fig. 3 shows the galvanostatic polarization curves of compounds of (I) as atypical example. Similar curves (not shown) were obtained for the other azo dye compounds. Inspection of Fig. 3 reveals that the presence of inhibitor shifts the anodic curves towards the noble direction and the cathodic curves towards the active one. This behaviour suggested the inhibitive effect of the additives. The various electrochemical parameters such as anodic $\left(\beta_{\mathrm{a}}\right)$ and cathodic $\left(\beta_{\mathrm{c}}\right)$ slopes, corrosion potential $\left(E_{\text {corr }}\right)$, corrosion current density $\left(I_{\text {corr }}\right)$, inhibition efficiency $(I E)$ and surface coverage were calculated from Tafel plots and given in Table (3). The value of corrosion current density was evaluated by the interaction of the extrapolated of the cathodic and anodic Tafel lines to the steady state corrosion.

An inspection of the data given in Table (3) reveals that increasing of concentrations of azo compounds (I-IV) causes:

i- The corrosion potential is shifted to more slightly positive values and the corrosion current density decreases indicating the inhibiting effect of the tested compounds.

ii- The values of the anodic and cathodic Tafel constants decreases slightly which suggests the simple blocking of the available surface area of the metal by the inhibitor molecules, i. e, the adsorbed inhibitor molecules decrease the surface area available for both metal dissolution and hydrogen evolution reactions without appreciably affecting the reaction mechanism [28]. Therefore, it could be concluded the values $\beta_{\mathrm{a}} \& \beta_{\mathrm{c}}$ are nearly constant. This indicate that the tested azo dye compounds effect on both the anodic and cathodic reactions i. e, it considered to be mixed type inhibitor.

iii- The values of inhibition efficiency and consequently the values of surface coverage increase with increasing the inhibitor concentration. The inhibition efficiency increases in the same order of the weight loss and thermometric results.

\section{Adsorption isotherm}

Naphthalene azo compounds (I-IV) inhibit the corrosion process of iron in $\mathrm{HCl}$ solutions by the adsorption of the azo dye molecules on the metal surface. The adsorption is regarded as substitutional adsorption process between the organic molecules in the aqueous phase $\left(\mathrm{Org}_{\mathrm{aq}}\right)$ and the water molecules adsorbed on the metal surface $\left(\mathrm{H}_{2} \mathrm{O}\right)_{\mathrm{ad}}[29]$

$$
\times \mathrm{H}_{2} \mathrm{O}_{\mathrm{ads}}+\mathrm{Org}_{\mathrm{sol}} \rightarrow \mathrm{Org}_{\mathrm{ads}}+\times \mathrm{H}_{2} \mathrm{O}_{\text {sol }}
$$

where $x$ is the size ratio, that is, the number of water molecules replaced by one organic molecule. Attempts were made to fit the surface coverage $(\theta)$ values to various adsorption isotherms including Frumkin, Langmuir, Temkin and Freundlich. By far, the results were best fitted by applying Temkin adsorption isotherm according to the following equation [30]:

$$
\theta=\text { Constant }+(2.303 / f) \log C
$$

where $f=1 / R T\left[\mathrm{~d}\left(\Delta \mathrm{G}^{\circ}{ }_{\mathrm{a}}\right)\right], \log C(C / \mathrm{M}), \Delta \mathrm{G}^{\circ}{ }_{\mathrm{a}}$ is the standard free energy of adsorption and $C$ is inhibitor concentration. Thus, on plotting $(\theta)$ obtained from weight loss method or polarization measurements versus $\log C$, straight line was obtained as shown in Fig. 5, denoting that adsorption of the tested azo dye compounds on the iron surface follows Temkin adsorption isotherm.

\section{Effect of temperature}

The effect of temperature on the corrosion rate of iron in $2 \mathrm{M} \mathrm{HCl}$ solutions in absence and in presence of the azo compounds (I-IV) was studied using weigh loss measurement at temperatures 313,323 and $333 \mathrm{~K}$. It was found that as the temperature increases, the corrosion rate increases and hence the inhibition efficiency decreases. This is may be to de-sorption of the inhibitor molecules at the metal surface which is aided by increasing temperature.

The activation energy $\left(E_{\mathrm{a}}\right)$ of the dissolution of the metal in the acid solution was calculated using the Arrhenius equation [31]: 


$$
R_{\text {corr }}=A \mathrm{e}^{-E_{\mathrm{a}} / R T}
$$

and the logarithmic form:

$$
\log R_{\text {corr }}=\log A-E_{\mathrm{a}} / 2.303 R T
$$

where $A$ is the Arrhenius constant, $R$ is the gas constant and $T$ is the absolute temperature.

On plotting log $R_{\text {corr }}\left(R_{\text {corr }} / \mathrm{mg} \mathrm{dm}^{-2}\right.$ day $\left.^{-1}\right)$ versus $1 / T$ for the free and inhibited solutions, straight lines were obtained Fig. (4). from the slopes of these plots, values of $E_{\mathrm{a}}$ were calculated and represented in Table (4). Inspection of Table, it is clear that the value of $E_{\mathrm{a}}$ increases in the presence of the inhibitors $(\mathrm{I}-\mathrm{IV})$ and the increase follows the order: IV $<$ III $<$ II $<$ I

The enthalpy change of activation $\left(\Delta H^{*}\right)$ was calculated applying the following relation [32]:

$$
\Delta H^{*}=E_{\mathrm{a}}-R T
$$

Also, the activation entropy change was calculated using the equation [31]:

$$
\Delta S^{*}=-\frac{\Delta G^{*}-\Delta H^{*}}{T}
$$

The values of $\Delta H^{*}, \Delta G^{*}$ and $\Delta S^{*}$ for corrosion of iron in hydrochloric acid solutions were calculated and given in Table (4). The data revealed that $\Delta H^{*}$ increases on increasing temperature, i. e, the dissolution of metal in the acidic medium is increased. On the other hand, at a given temperature, $\Delta H^{*}$ decreases in presence of the inhibitors (I-IV), the decrease follow the order: IV $<$ III $<$ II $<$ I

This means that the dissolution process decreases on going from azo compound I to azo compound IV. At the same time, the negative sign and decreasing of $\Delta S^{*}$ on increasing temperature denoting the increase of disorder accompanied the dissolution process. On the other hand, at the same temperature the negative sign and the negative sign and the increase of $\Delta S^{*}$ in presence of the inhibitor revealed that the disorder and consequently the dissolution process decreases in the sequence: IV $>$ III $>$ II $>$ I

\section{Quantum chemical calculations}

Experimental results show that inhibition efficiencies of the studied azo dye compounds can be due to the chemical adsorption of inhibitor molecules onto metal surface. Chemisorption involves the share or transfer of charge from the molecules to the surface to form a coordinate type bond. Electron transfer is typical for transition metals having vacant low-energy orbitals. As for inhibitors, the electron transfer can be expected with compounds having relatively loosely bound electrons [33-35].

To investigate the effect of molecular structure on the inhibition mechanism and the inhibition efficiency, some quantum chemical calculations were performed. Quantum chemical parameters such as the energy of the highest occupied molecular orbital, $E_{H}$, the energy of the lowest unoccupied molecular orbital, $E_{\mathrm{L}}$, the differences between them $\left(E_{\mathrm{L}}-E_{\mathrm{H}}\right)$, HOMO-LUMO gap, dipole moment, $\mu$, and the charge densities of molecules have been obtained from ab initio with basis set STO-3G method with commercially available quantum chemical software HyperChem, Release 8.0 and are given in Table (5), which show that an increase in the values of $E_{\mathrm{H}}$ and a decrease in $E_{\mathrm{L}}-E_{\mathrm{H}}$ values cause increase in the inhibitive action of the studied azo dye compounds. It is known that in the chemical adsorption an increase in $E_{\mathrm{H}}$ values cause a significant increase in the inhibition efficiency of organic compounds [36, 37].

On the other hand, the energy gap between $E_{\mathrm{L}}$ and $E_{\mathrm{H}}$ can be used as a characteristic quantity for metallic complexes [34, $35,38]$. The lower energy gap indicates the higher stability of the formed complex, thus the higher inhibition efficiency. Increase in $\mu$ values with the decrease of $E_{\mathrm{L}}-E_{\mathrm{H}}$ values indicates the formation of coordinate covalent bond between organic molecules and steel.

Figs. $6(\mathrm{a}, \mathrm{b})$ show the optimized geometry, the HOMO density distribution, the LUMO density distribution and the Mulliken charge population in aqueous phase. The reactive ability of the inhibitor is considered to be closely related to their frontier molecular orbitals, the $\mathrm{HOMO}$ and LUMO. Higher HOMO energy $\left(E_{\mathrm{H}}\right)$ of the molecule means a higher electron donating ability to appropriate acceptor molecules with low energy empty molecular orbital and thus explains the adsorption on metallic surfaces by way of delocalized pairs of p-electrons. $E_{\mathrm{L}}$, the energy of the lowest unoccupied molecular orbital signifies the electron receiving tendency of a molecule.

The number of electrons transferred $(\Delta N)$ was also calculated depending on the quantum chemical method, as in Eq. (13):

$$
\Delta N=\frac{X_{\mathrm{Fe}}-X_{\mathrm{inh}}}{2 \sum \eta_{\mathrm{Fe}}+\eta_{\mathrm{inh}}}
$$

where $X_{\mathrm{Fe}}$ and $X_{\mathrm{inh}}$ denote the absolute electronegativity of nickel and the inhibitor molecule, respectively; $\eta_{\mathrm{Fe}}$ and $\eta_{\mathrm{inh}}$ denote the absolute hardness of iron and the inhibitor molecule, the absolute electronegativity, $X$, and absolute hardness, $\eta$ is a chemical property that describes the ability of a molecule to attract electron towards itself in a covalent bond, while the absolute hardness is measured by the energy gap between the lowest unoccupied and highest occupied molecular orbitals [39]. Values of $X$ and $\eta$ were calculated by using the values of $I$ and $A$ obtained from quantum chemical 
calculation. Using a theoretical value of $X=7.0 \mathrm{eV} / \mathrm{mol}$, according to Pearson's electronegativity scale, and value of $\eta=$ $0.0 \mathrm{eV} / \mathrm{mol}$ for iron [40].

These parameters also provide information about the reactive behavior of molecules and are presented in Table (5). Absolute softness, $\sigma$ is defined as the reciprocal of the hardness. $X, \eta$ and $\sigma$ are calculated using the energies of the $\mathrm{HOMO}$ and the LUMO orbitals of the inhibitor molecule are related to the ionization potential $I$, and the electron affinity $A$, respectively, by the following relations:

$$
X=\frac{I+A}{2} ; \eta=\frac{I-A}{2} \text { and } \sigma=\frac{2}{I-A}
$$

where $I=-E_{\mathrm{HOMO}}$ and $A=-E_{\mathrm{LUMO}}$

The results deduced indicate that the electron flow will happen from the molecule with the low electronegativity towards that of a higher value, until the chemical potentials are the same. In our case, the best inhibitory effect is shown by azo dye compound IV with low electronegativity, but azo dye compound I possesses the higher value.

When the hardness $(\eta)$ values decrease, the inhibition values increases [41]. The opposite trend was obtained for softness $(\sigma)$ comparing with hardness, namely inhibition efficiency increases with softness [41-43] where high values of softness were found to favor the adsorption process [42]. Based on Table 5, the values of $\eta$ are always smaller, while those of $\sigma$ are always higher in presence of azo IV compared with azo I, II and III, reflecting the high inhibition performance of azo IV as compared with the other tested compounds.

$\Delta N$, the number of electrons transferred from inhibitor to the iron surface, was calculated. Values of $\Delta N$ showed that the inhibition effect resulted from electron donation. Based on Lukovits's study [44], $\Delta N<3.6$ denotes that the inhibition efficiency increases with increasing electron-donating ability at the metal surface. Based on these calculations, it is expected that the four tested inhibitors were donors of electrons, and the electrode surface was the acceptor, and this favours chemical adsorption of the inhibitor on the electrode surface. The compounds bind to the electrode surface and form an adsorption layer against corrosion. Azo dye compound IV had the highest inhibition efficiency because it had the highest $\Delta N$ values, and it had the greatest ability of offering electrons, and azo dye compound I had the lowest inhibition efficiency, for vice versa.

The dipole moment $(\mu)$ is another indicator of the electronic distribution in a molecule and is one of the properties used to discuss and to rationalize the structure [44]. Although, there is a lack of agreement in the literature on the correlation between the dipole moment and inhibition efficiency [45-48], the comparison between the calculated dipole moments of azo compounds (I-IV) reveals that the lowest (i.e. azo IV molecule) has better inhibition efficiency.

Table 6 shows that most of all $\mathrm{N}$ and some of $\mathrm{O}$ and $\mathrm{C}$ atoms carry negative charges. This indicates that these atoms are the negative charge centres which could offer electrons to the iron atoms on the surface to form a coordinate bond.

It is possible to evaluate condensed Fukui functions for nucleophilic, electrophilic, and radical attack from single-points calculations directly, without resorting to additional calculations involving the systems with $N, N-1$ and $N+1$ electron. The resulting change in electron density is the nucleophilic and electrophilic Fukui functions, which can be expressed using the finite difference approximation as follows,

$$
\begin{aligned}
& f_{\mathrm{K}}^{+}=q(N+1)-q(N) \\
& f_{\mathrm{K}}^{-}=q(N)-q(N-1)
\end{aligned}
$$

where $q(N), q(N+1)$ and $q(N-1)$ are the Mulliken charge of the atom with $N,(N+1)$, and $(N-1)$ electrons. Frontier orbital electron densities on atoms provide a useful means for the detailed characterization of donor-acceptor interactions. In the case of a donor molecule, the HOMO density is critical to the charge-transfer (electrophilic electron density $f_{\mathrm{K}}^{-}$) and in the case of an acceptor molecule, the LUMO density is important (nucleophilic electron density $f_{\mathrm{K}}^{+}$). However, frontier electron densities can strictly be used only to describe the reactivity of different atoms in the same molecule.

Table 6 present values of $f_{K}^{+}$and $f_{K}^{-}$for four inhibitors. As a rule, the respective site for electrophilic and nucleophilic attacks will be the place where the value of $f_{\mathrm{K}}^{+}$or $f_{\mathrm{K}}^{-}$is maximum. An analysis of Fukui indices shown in Table 6 , demonstrates that, in all inhibitors, the nitrogen atoms are the most susceptible sites for electrophilic attacks. These sites present the highest values of $f_{K}^{-}$.

The electrostatic potential is a physical property of a molecule related to how a molecule is first "seen" or "felt" by another approaching species [49]. A portion of a molecule that has a negative electrostatic potential will be susceptible to 
electrophilic attack. The more the negative the electrostatic potential, the higher is the susceptible to electrophilic attack. It is not as straightforward to use electrostatic potentials to predict nucleophilic attack. The three dimensional mapped isosurface of the electrostatic potential (ESP) of inhibitors are shown in Fig. 7 (a, b) using ab initio method as implemented in the HyperChem version 8.0 program. This map provides information on the reactivity of the molecules in actual reaction with electrophiles or nucleophiles. Red colors indicate negative ESP regions and green colors indicate positive ESP regions. These Figs. show that nitrogen and oxygen atoms have more negative ESP regions in compare with other atoms. This means that oxygen and nitrogen atoms undergo protonation reaction with acidic reagents [50].

\section{CONCLUSIONS}

All studied azo dye compounds behave as efficient corrosion inhibitors and their inhibition efficiencies tend to increase with increasing inhibitor concentration. The protection ability of these compounds is given in the order of IV $<$ III $<$ II $<$ I. All studied azo dye compounds acts as a mixed type inhibitors for acidic corrosion of iron in $2 \mathrm{M} \mathrm{HCl}$. The inhibition action of the studied compounds is mainly due to their blocking adsorption on the steel surface. Adsorption process obeys Temkin isotherm.

The inhibition efficiencies of the studied azo dye compounds increases with increasing $E_{\mathrm{H}}$ and with decreasing $\Delta E$ value.

The values of free energy of adsorption and the relationship between the inhibition efficiency values and the calculated quantum chemical parameters suggest that these azo dye compounds can be adsorbed on steel surface by chemical mechanism.

Data obtained from quantum chemical calculations ab initio with basis set STO-3G method level of theory were correlated to the inhibitive effect of azo dye compounds. Both experimental and theoretical calculations are in excellent agreement.

\section{REFERENCES}

[1] Lagrenee M, Mernari B, Bouanis M, Traisnel M, Bentiss F, 2000. Study of the mechanism and inhibiting efficiency of 3,5-bis(4-methylthiophenyl)-4H-1,2,4-triazole on mild steel corrosion in acidic media, Corros Sci., 44(3):573-588.

[2] Bentiss F, Lagrenee M, Traisnel M, Hornez J.C, 1999. The corrosion inhibition of mild steel in acidic media by a new triazole derivative, Corrs Sci., 41(4): 789-803.

[3] Mabrouk E.M, Shokry H, Abu AL-Naja K.M, 2011. Inhibition of aluminum corrosion in acid solution by mono- and bisazo naphthylamine dyes. Part 1, Chem Met Alloys 4, 98-106.

[4] McCafferty, E. Pravdic, V. Zettlemoyer, A.C., 1999. Trans Faraday Soc., 66:237-241.

[5] Zor S, Yazici B, Erbil M 2005. Inhibition effects of LAB and LABS on iron corrosion in chlorine solutions at different temperatures, Corros Sci., $47(11): 2700-2710$.

[6] Jeyaprabha, C. Sathiyanarayanan, S. Venkatachari, G., 2006. Influence of halide ions on the adsorption of diphenylamine on iron in $0.5 \mathrm{M} \mathrm{H}_{2} \mathrm{SO}_{4}$ solutions, Electrochem Acta, 51(19):4080-4088.

[7] Chetuani, A. Hammouti, B. Benhadda, T. Daoudi, M., 2005. Inhibitive action of bipyrazolic type organic compounds towards corrosion of pure iron in acidic media, Appl Surf Sci., 249(1-4):375-385.

[8] Abd El-Maksoud S.A., 2002. Studies on the effect of pyranocoumarin derivatives on the corrosion of iron in $0.5 \mathrm{M} \mathrm{HCl}$, Corros Sci., 44(4):803-813.

[9] Khaled, K.F., 2004. An electrochemical study for corrosion inhibition of iron by some organic phosphonium chloride derivatives in acid media, Appl Surf Sci., 230(1-4):307-318.

[10] Abdel-Rehim, SS. Khaled, KF. Abd El-Shafi, NS., 2006. Electrochemical frequency modulation as a new technique for monitoring corrosion inhibition of iron in acid media by new thiourea derivative, Electrochem Acta, 51(16):3269-3277.

[11] Khairou, KS. Zaafarany, I., 2006.Some sulfated water soluble natural polymer (Carrageenans) compounds as corrosion inhibitors for dissolution of iron in hydrochloride acid solution, Mater Sci Research India, 3(2):135-140.

[12] Khaled, KF., 2008. Application of electrochemical frequency modulation for monitoring corrosion and corrosion inhibition of iron by some indole derivatives in molar hydrochloric acid, Mater Chem Phys, 112(1):290-300.

[13] Abdallah, M. El-Etre, AY. Soliman, MG., Mabrouk EM., 2006.Some organic and inorganic compounds as inhibitors for carbon steel corrosion in 3.5 percent $\mathrm{NaCl}$ solution, Anti-Corrosion Methods and Materials, 53(2):118-123.

[14] Fouda AS, Elewady GY, El-Haddad MN., 2011. Corrosion inhibition of carbon steel in acidic solution using some azodyes, Canadian J Scientific and Industrial Research, 2(1):1-18.

[15] Ying Yana b, Weihua Lib, Lankun Caia, Baorong Houb., 2008. Electrochemical and quantum chemical study of purines as corrosion inhibitors for mild steel in $1 \mathrm{M} \mathrm{HCl}$ solution, Electrochimica Acta, 53(20):5953-5960.

[16] Obi-Egbedi, N.O. Essien, K.E. Obot, I.B. Ebenso, E.E., 1, 2 - Diaminoanthraquinone as Corrosion Inhibitor for mild steel in hydrochloric acid: Weight loss and Quantum Chemical study, Int J Electrochem Sci., 6:913-930. 
[17] Pournazaria, Sh. Moayeda, M.H. Rahimizadehb, M., 2013. In situ inhibitor synthesis from admixture of benzaldehyde and benzene-1,2-diamine along with $\mathrm{FeCl} 3$ catalyst as a new corrosion inhibitor for mild steel in $0.5 \mathrm{M}$ sulphuric acid , Corros Sci., 71:20-31.

[18] Obi-Egbedi, N.O. Obot, I.B. El-Khaiary, M.I. Umoren, S.A. Ebenso, E.E., 2011. Computational simulation and statistical analysis on the relationship between corrosion inhibition efficiency and molecular structure of some phenanthroline derivatives on mild steel surface, Int. J Electrochem Sci., 6:5649-5675.

[19] Amin, MA. Shokry, H. Mabrouk, EM., 2012. Nickel Corrosion Inhibition in Sulfuric Acid - Electrochemical Studies, Morphologies, and Theoretical Approach, Corros, 68(8):699-712.

[20] Conant, J.B., Lutz, R.E., Corson, B.B., Organic Syntheses Collective, Volume I John Wiley \& Sons New York, (1941).

[21] Bardford, SL., Corrosion Control, Van Nostrand Reinhold New York, 1993.

[22] Chin, RJ. Nobe, K., 1971. Electrochemical Characteristics of Iron in $\mathrm{H}_{2} \mathrm{SO}_{4}$ Containing Benzotriazole , J Electrochem Soc., 118(3):545-548.

[23] Mylius, F.Z., Metallk,(1922)14:233-239.

[24] HyperChem, Hypercube Inc Gainesville (2002).

[25] Wolinski, K. Hinton, J.F. Pulay, P., 1990. Efficient implementation of the gauge-independent atomic orbital method for NMR chemical shift calculations, J Am Chem Soc, 12(1):8251-8260.

[26] Dewar, MJS. Liotard, DA., 1990. An efficient procedure for calculating the molecular gradient, using SCF-Cl semiempirical wavefunctions with a limited number of configurations, J Mol Struct (Theochem), 206(1-2):123-133.

[27] Leunberger, D.G., Introduction to linear and non-linear programming Addison-Wesley Don Mills Ont, (1973).

[28] El-Sayed, A. Shaker, A.M. Abd El-Lateef, H.M., 2010. Corrosion inhibition of tin, indium and tin-indium alloys by adenine or adenosine in hydrochloric acid solution, Corros Sci., 52(1):72-81.

[29] Moretti, G. Quartorone, G. Tassan, A. Zingales, A., 1994. Werkst. Korros, (1994) 45:641-647

[30] Conway, B.E., Theory and Principles of Electrode Processes, The Ronald Press Co New York (1965) 81:170-272.

[31] Atkins, P.W. Physical Chemistry, 3rd Ed Oxford Univ Great Britain,(1994) 750-751.

[32] Laidler, KJ., 1979. Chem Mcical Kinetics, Tata Mc Graw Pub Co New Delh, (1979).

[33] Mansfeld, F., Corrosion Mechanisms, Marcel Dekker New York, (1987) 119-121.

[34] Yurt, A. Bereket, G. Kıvrak, A. Balaban, A. Erk, B., 2005. Effect of Schiff Bases Containing Pyridyl Group as Corrosion Inhibitors for Low Carbon Steel in 0.1 M HCl, 2005. J Appl Electrochem., 35(10):1025-1032.

[35] Yurt Bereket, A. retir, GO"g־., 2005. Quantum chemical studies on inhibition effect of amino acids and hydroxy carboxylic acids on pitting corrosion of aluminium alloy 7075 in NaCl solution, J Mol Struct THEOCHEM , 725:215-221.

[36] S. Li, S. Chen, S.Lei, H. Ma, R. Yu, D. Liu, 1999. Investigation on some Schiff bases as HCl corrosioninhibitors for copper, Corros Sci., 41(7):1273-1287.

[37] Li, SL. Wang, YG. Chen, SH. Yu, R. Lei, SB. Ma, HY. Liu, DX., 1999. Some aspects of quantum chemical calculations for the study of Schiff base corrosion inhibitors on copper in NaCl solutions, Corros Sci., 41(9):1769-1782.

[38] Cherry, W. Epiotis, N.T. Borden, W., 1977. Effects of filled .pi. and unfilled .sigma. molecular orbital interactions on molecular structure, Acc Chem Res., 10(2):167-173.

[39] Khaled, KF., 2010. Corrosion control of copper in nitric acid solutions using some amino acids - A combined experimental and theoretical study, Corros Sci., 52(10):3225-3234.

[40] Arslan, T. Kandemirli, F. Ebenso, EE. Love, I. Alemu, H., 2009. Quantum chemical studies on the corrosion inhibition of some sulphonamides on mild steel in acidic medium, Corros Sci., 51(1):35-47.

[41] Amin, MA. Ahmed, MA. Arida, HA. Kandemirli, F. Saracoglu, M. Arslan, T. Basaran, MA., 2011. Monitoring corrosion and corrosion control of iron in $\mathrm{HCl}$ by non-ionic surfactants of the TRITON-X series - Part III. Immersion time effects and theoretical studies, Corros Sci., 53(5):1895-1909.

[42] Issa, R.M. Awad, M.K. Atlam, F.M., 2008.Quantum chemical studies on the inhibition of corrosion of copper surface by substituted uracils, Appl Surf Sci 255(5):2433-2441.

[43] Lukovits, L. Kalman, E. Zucchi, F., 2001. Corrosion Inhibitors-Correlation Between Electronic Structure and Efficiency, Corrosion, 57(1):3-8.

[44] Kikuchi, O., Systematic QSAR Procedures with Quantum Chemical Descriptors, Quant Struct Act Relat., (1987) 6(4):179-184.

[45] Gao, G. Liang, C., 2007. Electrochemical and DFT studies of $\beta$-amino-alcohols as corrosion inhibitors for brass , Electrochimic Acta, 52(13): 4554-4559. 
[46] Khalil, N., Quantum chemical approach of corrosion inhibition, Electrochimic Acta, 48(18):2635-2640.

[47] Rodrigez-Valdez, LM. Martinez-Villafane, A. Glossman-Mitnik, D., 2005. Computational simulation of the molecular structure and properties of heterocyclic organic compounds with possible corrosion inhibition properties, J Mol Struct, 713(1-3):65-70.

[48] Stoyanova, A. Petkova, G. Peyerimhoff, S.D., 2002. Correlation between the molecular structure and the corrosion inhibiting effect of some pyrophthalone compounds, Chem Phys., 279(1):1-6.

[49] Pearson, R.G., 1986. Absolute electronegativity and hardness correlated with molecular orbital theory, Proc Nati Acad Sci., 83: 8440-8441.

[50] Pearson, RG., 1988. Absolute electronegativity and hardness: application to inorganic chemistry, Inorg Chem, 27(4):734-740.

\section{FIGURES/CAPTIONS}

Fig. 1 Molecular structure of investigated azo dye compounds (I-IV).

Fig. 2 Variation of temperature with time at different concentrations of compound (I) for iron in $2 \mathrm{M} \mathrm{HCl}$.

Fig. 3 Galvanostatic polarization curves for the corrosion of iron in $0.1 \mathrm{M} \mathrm{HCl}$ in absence and in presence of different concentrations of compound (I).

Fig. 4 Arrhenius plots of the corrosion rate of iron in $2 \mathrm{M} \mathrm{HCl}$ in absence and in presence of inhibitors (I, II, II, IV).

Fig. 5 Temkin adsorption isotherm of monoazo compound (I) for iron in $2 \mathrm{M} \mathrm{HCl}$.

Fig. 6 (a) The highest occupied molecular orbital (HOMO) and (b) The lowest unoccupied molecular orbital (LUMO) density azo compounds (I-IV) using the HyperChem version 8.0 program.

Fig. 7 ( $a \& b)$ 3D maps Isosurface of the electrostatic potential (ESP) in the spatial vicinity of inhibitors (I-IV) (the electron rich region is red and the electron poor region is green in the neutral molecules), using ab initio method as implemented in the HyperChem version 8.0 program.

\section{Figure 2}

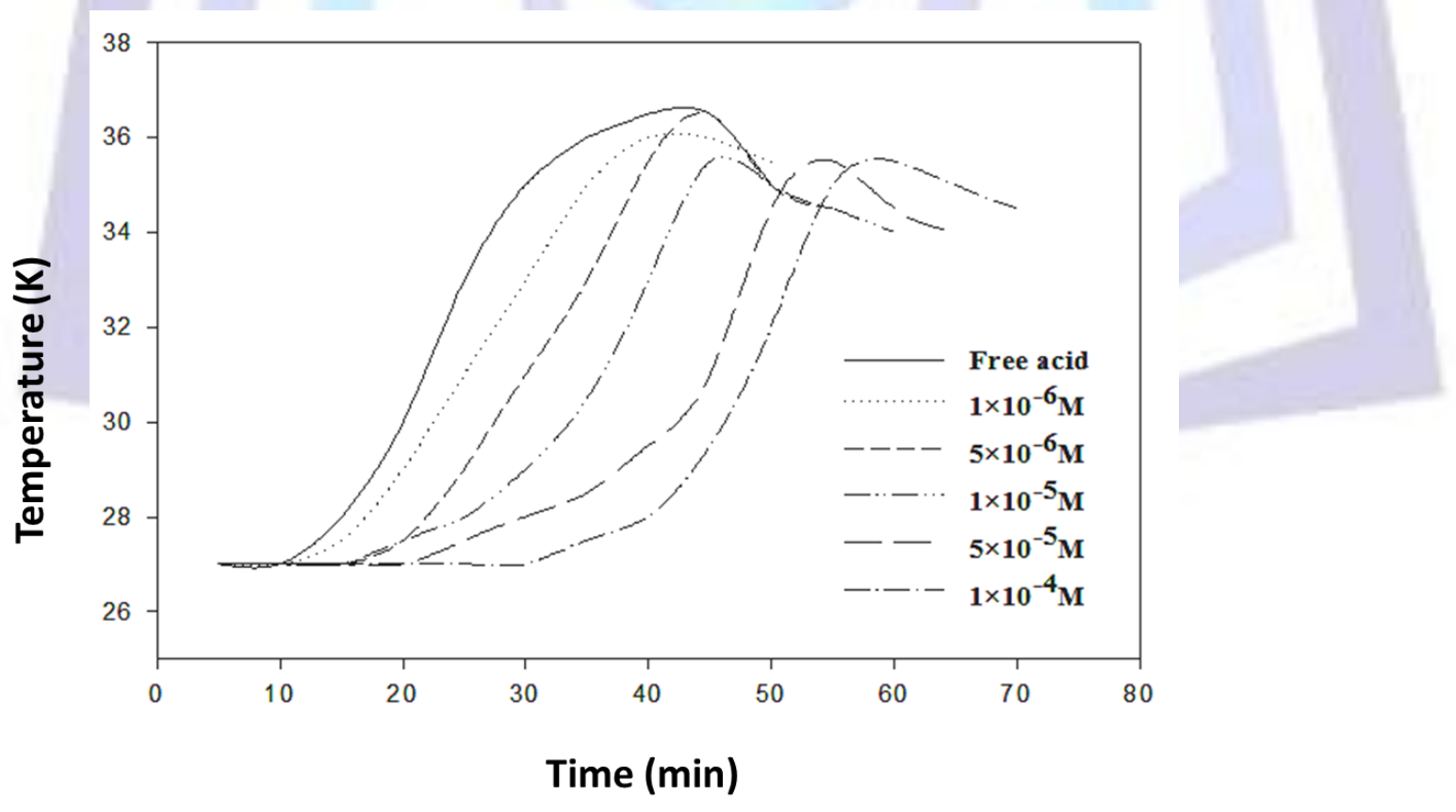


Figure 3

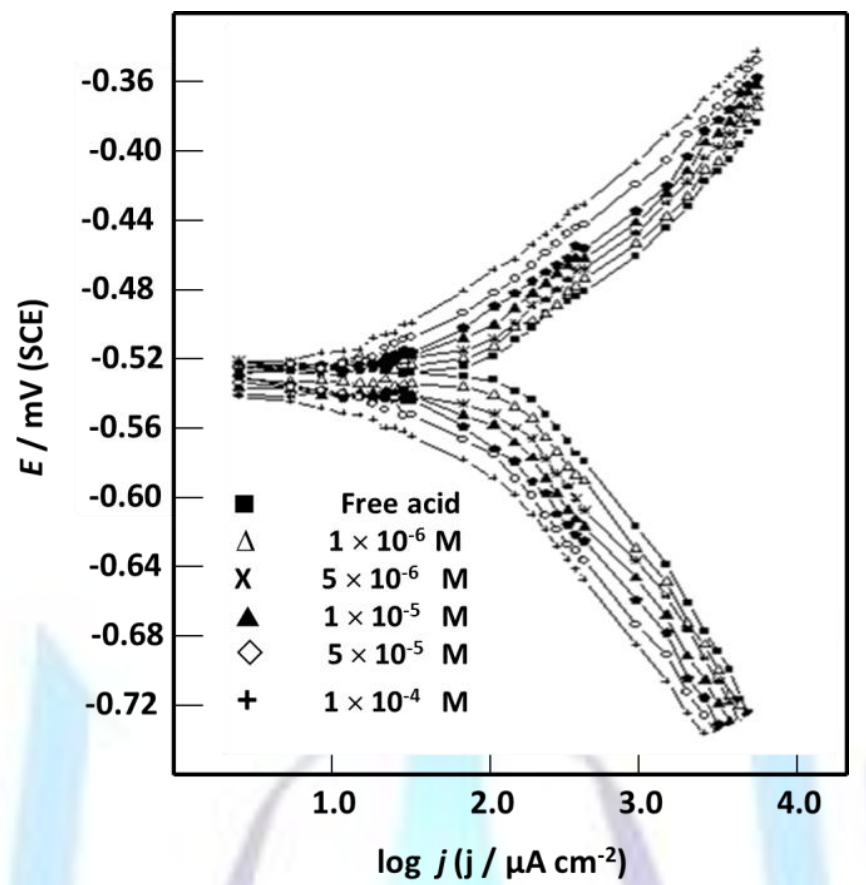

Figure 4

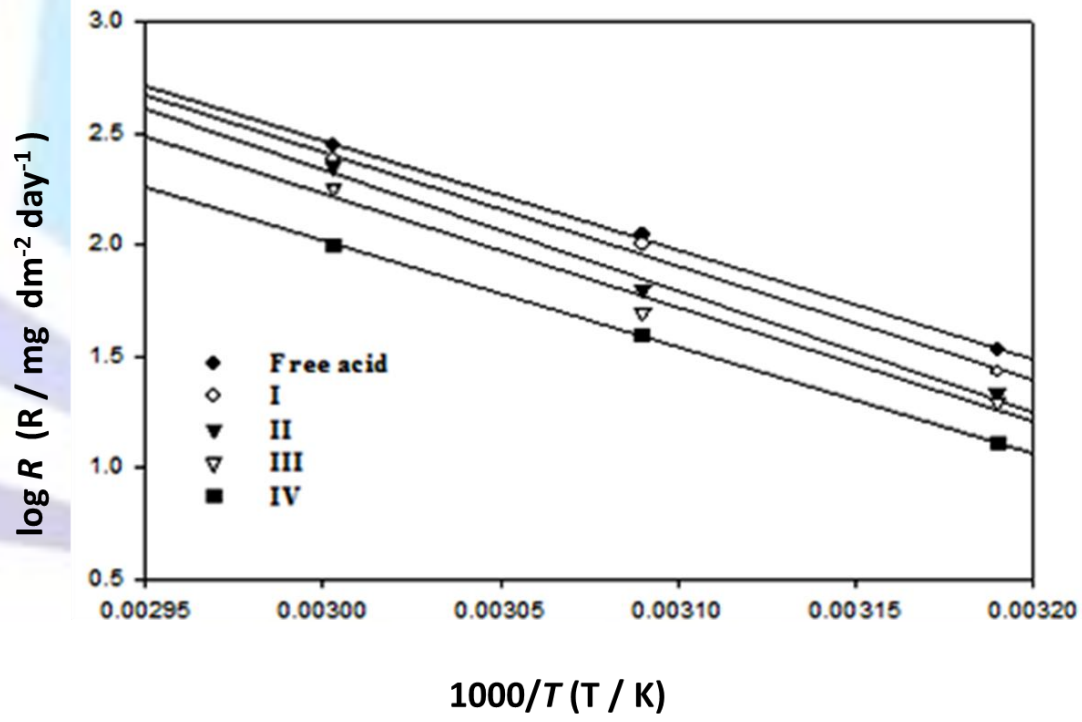


Figure 5

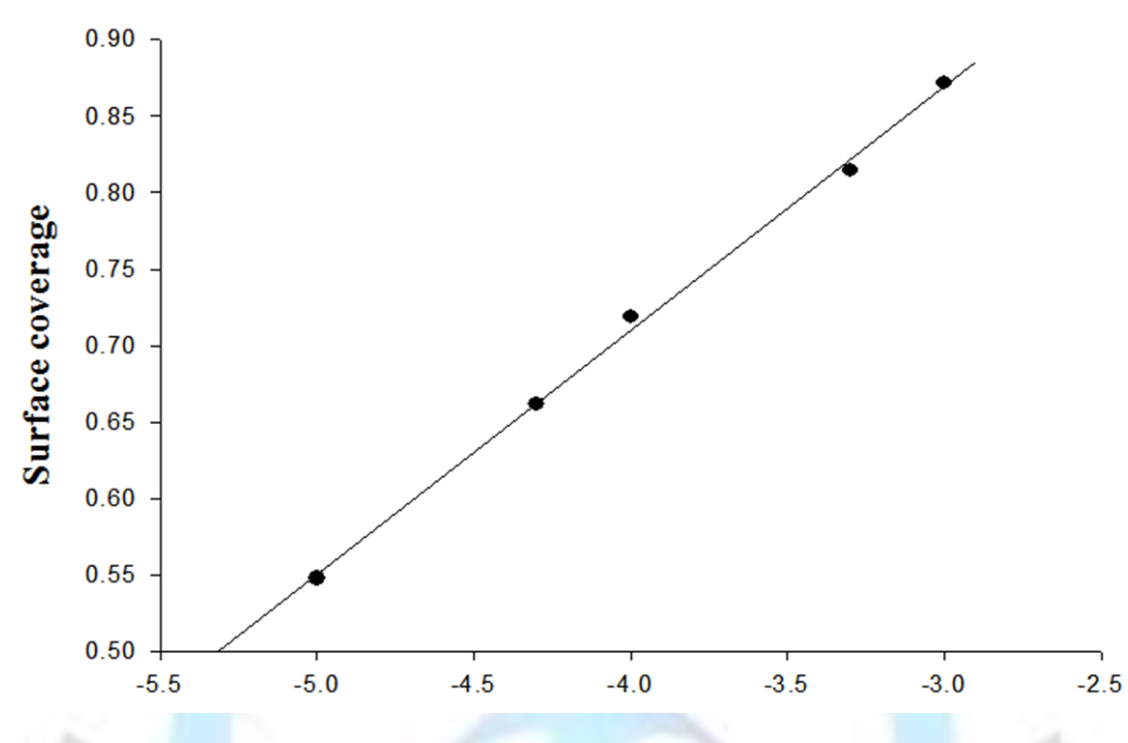

$\log C(C / M)$

Figure 6

(a) номо
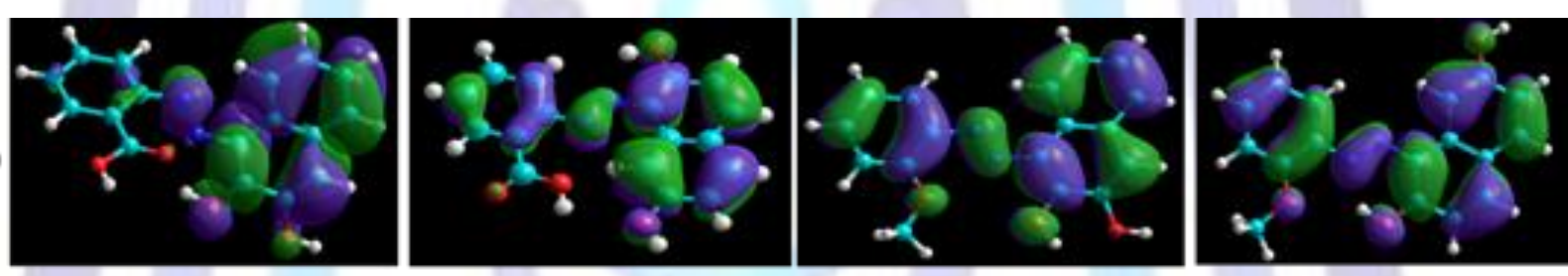

(b) LUMO

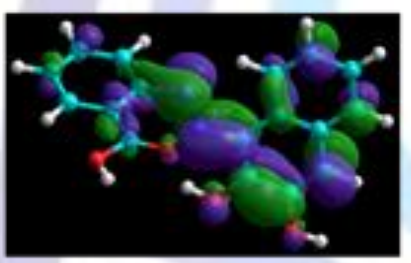

I

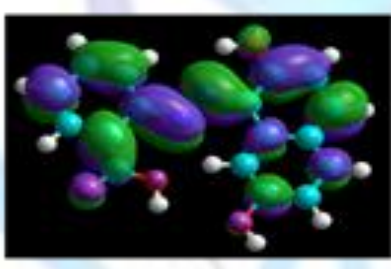

II

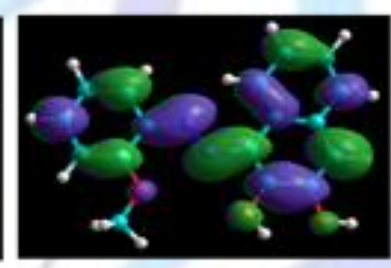

III

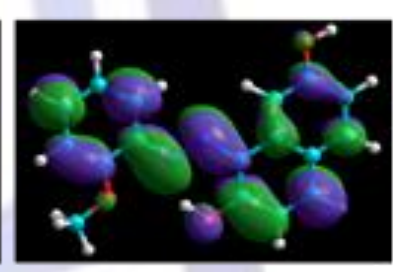

IV

Figure 7

(a)
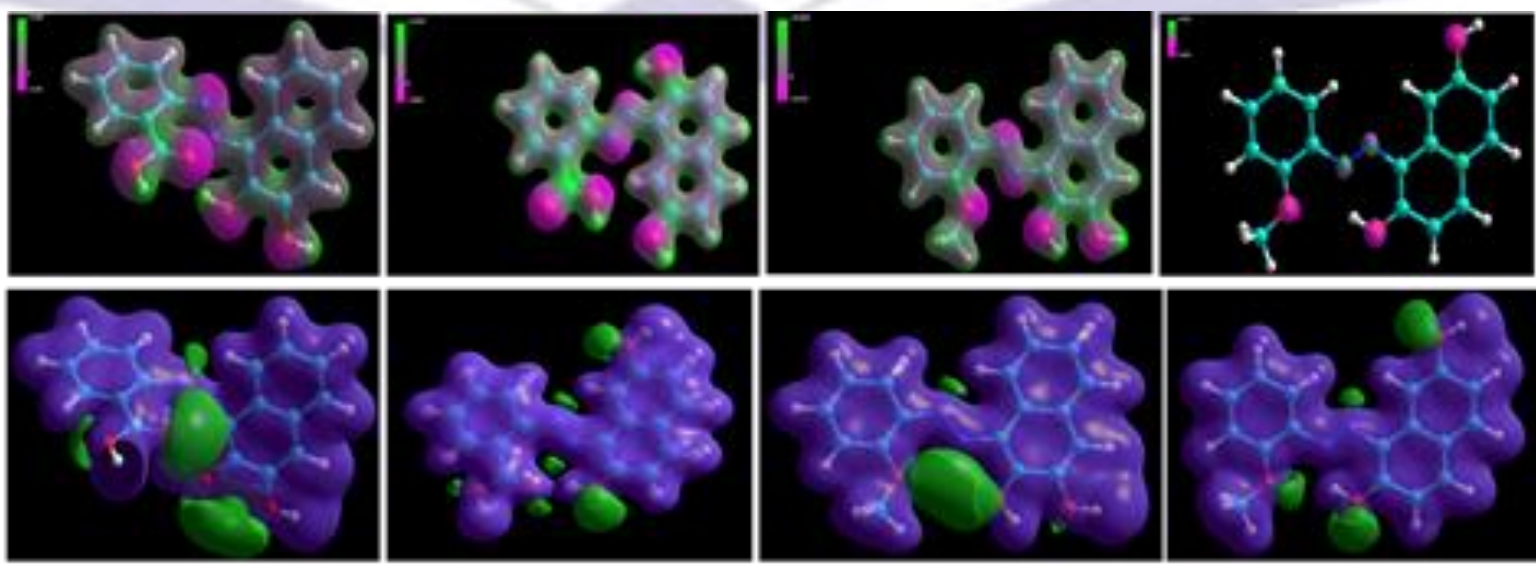

II

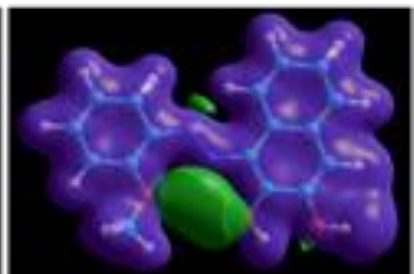

III

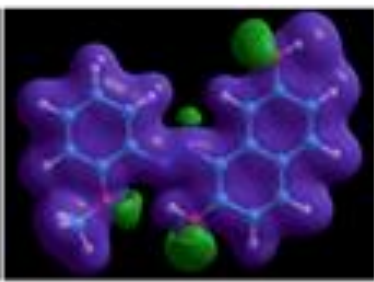

IV 
Table 1 Corrosion parameters of iron in $2 \mathrm{M}$ hydrochloric acid solution in presence of different concentrations of azo dye compounds (I-IV) using weight loss method.

\begin{tabular}{|c|c|c|c|c|}
\hline \multirow[t]{2}{*}{ Compd. } & {$[C]$} & $R$ & $I E \%$ & $\theta$ \\
\hline & M & \multicolumn{3}{|l|}{$\mathrm{mg} \mathrm{dm}^{-2}$ day $^{-1}$} \\
\hline \multirow[t]{5}{*}{$\mathrm{I}$} & $1 \times 10^{-6}$ & 11.40 & 50.00 & 0.500 \\
\hline & $5 \times 10^{-6}$ & 9.48 & 61.27 & 0.613 \\
\hline & $1 \times 10^{-5}$ & 8.76 & 64.90 & 0.649 \\
\hline & $5 \times 10^{-5}$ & 6.96 & 72.38 & 0.723 \\
\hline & $1 \times 10^{-4}$ & 5.76 & 77.14 & 0.771 \\
\hline \multirow[t]{5}{*}{ II } & $1 \times 10^{-6}$ & 10.92 & 54.76 & 0.548 \\
\hline & $5 \times 10^{-6}$ & 4.48 & 62.32 & 0.624 \\
\hline & $1 \times 10^{-5}$ & 7.08 & 71.90 & 0.719 \\
\hline & $5 \times 10^{-5}$ & 4.68 & 81.42 & 0.814 \\
\hline & $1 \times 10^{-4}$ & 3.24 & 87.14 & 0.871 \\
\hline \multirow[t]{5}{*}{ III } & $1 \times 10^{-6}$ & 10.44 & 56.66 & 0.567 \\
\hline & $5 \times 10^{-6}$ & 8.64 & 65.71 & 0.657 \\
\hline & $1 \times 10^{-5}$ & 6.36 & 74.76 & 0.748 \\
\hline & $5 \times 10^{-5}$ & 5.04 & 80.00 & 0.800 \\
\hline & $1 \times 10^{-4}$ & 3.72 & 85.23 & 0.852 \\
\hline \multirow[t]{5}{*}{ IV } & $1 \times 10^{-6}$ & 10.20 & 59.52 & 0.595 \\
\hline & $5 \times 10^{-6}$ & 8.52 & 66.19 & 0.662 \\
\hline & $1 \times 10^{-5}$ & 7.32 & 70.95 & 0.710 \\
\hline & $5 \times 10^{-5}$ & 6.96 & 72.38 & 0.748 \\
\hline & $1 \times 10^{-4}$ & 5.76 & 77.14 & 0.771 \\
\hline
\end{tabular}

Table 2 Corrosion parameters of iron in $\mathbf{2} \mathbf{M}$ hydrochloric acid solutions containing different concentrations of azo compounds (I-IV) using thermometric method.

\begin{tabular}{ccccccccc}
\hline Compd. & \multicolumn{2}{c}{ I } & \multicolumn{2}{c}{ II } & \multicolumn{2}{c}{ III } & \multicolumn{3}{c}{ IV } \\
\hline$[C] \mathrm{M}$ & $R N$ & IE & $R N$ & IE & $R N$ & $I E$ & $R N$ & $I E \%$ \\
0.0 & 0.231 & - & & & & & & \\
$1 \times 10^{-6}$ & 0.133 & 42.42 & 0.118 & 48.92 & 0.103 & 55.41 & 0.096 & 58.44 \\
$5 \times 10^{-6}$ & 0.120 & 48.05 & 0.105 & 54.55 & 0.090 & 61.04 & 0.088 & 62.34 \\
$1 \times 10^{-5}$ & 0.108 & 53.25 & 0.090 & 61.04 & 0.080 & 65.37 & 0.077 & 66.67 \\
$5 \times 10^{-5}$ & 0.082 & 64.50 & 0.078 & 66.23 & 0.073 & 68.40 & 0.069 & 70.13 \\
$1 \times 10^{-4}$ & 0.070 & 69.70 & 0.067 & 70.99 & 0.065 & 71.86 & 0.063 & 72.73 \\
\hline
\end{tabular}


Table 3 Corrosion parameters of iron in $0.1 \mathrm{M}$ hydrochloric acid solutions in presence of different concentrations of azo compounds (I-IV), using galvanostatic measurements.

\begin{tabular}{|c|c|c|c|c|c|c|c|}
\hline Compd. & {$[C]$} & $\begin{array}{c}-E_{\text {corr }} \\
m V(S C F)\end{array}$ & $I_{\text {corr }}$ & $B_{a}$ & BC & $\theta$ & $I E \%$ \\
\hline \multirow[t]{6}{*}{ I } & 0.00 & 533 & 568.35 & 76 & 115 & - & - \\
\hline & $1 \times 10^{-6}$ & 530 & 296.28 & 66 & 105 & 0.480 & 47.96 \\
\hline & $5 \times 10^{-6}$ & 531 & 261.86 & 60 & 102 & 0.540 & 54.00 \\
\hline & $1 \times 10^{-5}$ & 528 & 231.26 & 58 & 99 & 0.594 & 59.38 \\
\hline & $5 \times 10^{-5}$ & 528 & 188.22 & 53 & 93 & 0.670 & 66.94 \\
\hline & $1 \times 10^{-4}$ & 526 & 180.12 & 50 & 91 & 0.684 & 68.30 \\
\hline \multirow[t]{6}{*}{ II } & 0.00 & 533 & 568.35 & 76 & 115 & - & - \\
\hline & $1 \times 10^{-6}$ & 531 & 271.15 & 72 & 112 & 0.524 & 52.37 \\
\hline & $5 \times 10^{-6}$ & 528 & 250.05 & 70 & 106 & 0.561 & 56.10 \\
\hline & $1 \times 10^{-5}$ & 526 & 221.56 & 65 & 105 & 0.611 & 61.08 \\
\hline & $5 \times 10^{-5}$ & 525 & 180.56 & 61 & 98 & 0.683 & 68.30 \\
\hline & $1 \times 10^{-4}$ & 524 & 170.22 & 58 & 100 & 0.702 & 70.20 \\
\hline \multirow[t]{6}{*}{ III } & 0.00 & 533 & 568.35 & 76 & 115 & - & - \\
\hline & $1 \times 10^{-6}$ & 531 & 260.22 & 72 & 113 & 0.543 & 54.30 \\
\hline & $5 \times 10^{-6}$ & 530 & 244.23 & 72 & 109 & 0.571 & 57.10 \\
\hline & $1 \times 10^{-5}$ & 528 & 215.25 & 71 & 106 & 0.622 & 62.20 \\
\hline & $5 \times 10^{-5}$ & 523 & 170.33 & 66 & 103 & 0.701 & 70.01 \\
\hline & $1 \times 10^{-4}$ & 522 & 152.28 & 65 & 103 & 0.732 & 73.2 \\
\hline \multirow[t]{6}{*}{ IV } & 0.00 & 533 & 568.35 & 76 & 115 & - & - \\
\hline & $1 \times 10^{-6}$ & 531 & 254.35 & 77 & 101 & 0.521 & 55.21 \\
\hline & $5 \times 10^{-6}$ & 529 & 238.28 & 77 & 101 & 0.581 & 58.07 \\
\hline & $1 \times 10^{-5}$ & 527 & 208.03 & 74 & 99 & 0.634 & 63.39 \\
\hline & $5 \times 10^{-5}$ & 522 & 160.22 & 65 & 100 & 0.718 & 71.81 \\
\hline & $1 \times 10^{-4}$ & 522 & 148.29 & 63 & 104 & 0.739 & 73.92 \\
\hline
\end{tabular}


Table 4 Thermodynamic activation parameters of corrosion of iron in free and inhibited $2 \mathrm{M} \mathrm{HCl}$ acid solutions in presence of $1 \times 10^{-3} \mathrm{M}$ azo dye compounds (I-IV) using weight loss method.

\begin{tabular}{cccccc}
\hline Compd. & $\begin{array}{c}\text { Temp. } \\
\text { K }\end{array}$ & $\begin{array}{c}E_{\mathrm{a}}{ }^{*} \\
\mathrm{~kJ}\end{array}$ & $\begin{array}{c}\Delta H^{*} \\
\mathrm{kJmol}^{-1}\end{array}$ & $\begin{array}{c}\Delta \mathrm{G}^{*} \\
\mathrm{kJmol}^{-1}\end{array}$ & $\begin{array}{c}\Delta S^{*} \\
\mathrm{Jmol}^{-1}\end{array}$ \\
\hline Free acid & 313 & 370.99 & -2230.04 & 76444.27 & -251.35 \\
& 323 & & -2313.14 & 74538.29 & -237.93 \\
& 333 & & -2396.24 & 75877.44 & -235.05 \\
I & 313 & 433.71 & -2167.32 & 77328.62 & -253.98 \\
& 323 & & -2250.42 & 74753.02 & -238.40 \\
II & 333 & & -2333.52 & 75988.13 & -235.20 \\
& 313 & 475.50 & -2125.53 & 77510.69 & -254.42 \\
& 323 & & -2208.63 & 75316.68 & -240.01 \\
III & 333 & & -2291.73 & 76071.15 & -235.32 \\
& 313 & 527.77 & -2073.26 & 77874.83 & -255.42 \\
& 323 & & -2156.36 & 76126.49 & -242.36 \\
IV & 333 & & -2239.46 & 76126.49 & -235.33 \\
& 313 & 580.02 & -2021.01 & 78499.08 & -257.25 \\
& 323 & & -2104.11 & 75719.30 & -240.93 \\
& 333 & & -2187.21 & 76818.30 & -237.25 \\
\hline
\end{tabular}

Table 5 Quantum chemical parameters for the studied inhibitors calculated with ab initio method in gas phase as implemented in the HyperChem version 8.0 program.

\begin{tabular}{ccccc}
\hline Parameters & I & II & III & IV \\
\hline$E_{\text {HOMO }}(\mathrm{eV})$ & -7.92 & -7.74 & -7.45 & -7.15 \\
$E_{\text {LUMO }}(\mathrm{eV})$ & 1.69 & 1.6 & 1.79 & 1.53 \\
$\Delta E(\mathrm{eV})$ & 9.61 & 9.34 & 9.24 & 8.68 \\
$X$ & 3.115 & 3.07 & & \\
$\eta$ & 4.805 & 4.67 & 2.83 & 2.81 \\
$\sigma$ & 0.208 & 0.214 & 4.62 & 0.230 \\
$\Delta N$ & 0.0400 & 0.0460 & 0.216 & 0.079 \\
$\mu($ Debye $)$ & 1.505 & 2.10 & 0.0725 & 0.863 \\
\hline & & & 2.335 & \\
\hline
\end{tabular}


Table 6 Calculated Mulliken atomic charges and Fukui functions for inhibitors.

\begin{tabular}{|c|c|c|c|c|c|c|c|}
\hline Inhibitor & Atom & $q(N)$ & $q(N-1)$ & $q(N+1)$ & $f_{\mathrm{K}}^{+}$ & $f_{\mathrm{K}}^{-}$ & $f_{\mathrm{K}}^{\mathrm{o}}$ \\
\hline \multirow[t]{23}{*}{ I } & $\mathrm{C}(1)$ & 0.2439 & 0.3522 & 0.3650 & 0.1211 & 0.1083 & 0.0063 \\
\hline & $C(2)$ & 0.4530 & 0.4338 & 0.4798 & 0.0268 & -0.0192 & 0.0230 \\
\hline & $\mathrm{C}(3)$ & 0.3779 & 0.3295 & 0.4944 & 0.1164 & -0.0484 & 0.0824 \\
\hline & $C(4)$ & -0.2015 & 0.1319 & 0.2600 & 0.4616 & 0.3334 & 0.0640 \\
\hline & $C(5)$ & -0.0552 & -0.1045 & -0.0859 & -0.0306 & -0.0493 & 0.0093 \\
\hline & $\mathrm{C}(6)$ & -0.1122 & -0.2028 & -0.2055 & -0.0933 & -0.0906 & -0.0013 \\
\hline & $\mathrm{C}(7)$ & -0.1921 & 0.0758 & 0.1654 & 0.3576 & 0.2679 & 0.0448 \\
\hline & $\mathrm{C}(8)$ & -0.2396 & -0.0036 & 0.0931 & 0.3328 & 0.2359 & 0.0484 \\
\hline & $\mathrm{C}(9)$ & -0.2325 & -0.0161 & 0.0970 & 0.3295 & 0.2163 & 0.0566 \\
\hline & $C(10)$ & -0.2045 & 0.1551 & 0.1552 & 0.3597 & 0.3597 & 0.0031 \\
\hline & $\mathrm{O}(11)$ & -0.2407 & -0.4287 & -0.6578 & -0.4171 & -0.1879 & -0.1145 \\
\hline & $\mathrm{O}(12)$ & -0.2276 & -0.7336 & -0.7923 & -0.5647 & -0.5060 & -0.0293 \\
\hline & $\mathrm{N}(13)$ & -0.4731 & -0.5490 & -0.5675 & -0.0944 & -0.0759 & -0.0092 \\
\hline & $\mathrm{N}(14)$ & -0.3577 & -0.2952 & -0.3873 & -0.0295 & 0.0624 & -0.0460 \\
\hline & $C(15)$ & 0.3147 & 0.2541 & 0.2868 & -0.0279 & -0.0606 & 0.0163 \\
\hline & $C(16)$ & -0.2122 & -0.0470 & 0.0327 & 0.2450 & 0.1652 & 0.0399 \\
\hline & $C(17)$ & -0.2454 & -0.0443 & 0.0410 & 0.2864 & 0.2010 & 0.0426 \\
\hline & $C(18)$ & -0.1792 & 0.0781 & 0.1344 & 0.3137 & 0.2574 & 0.0281 \\
\hline & $C(19)$ & -0.2588 & -0.2308 & -0.2027 & 0.0560 & 0.0280 & 0.0140 \\
\hline & $C(20)$ & -0.2174 & 0.0424 & 0.1154 & 0.3329 & 0.2599 & 0.0365 \\
\hline & $C(21)$ & 0.9717 & 0.9483 & 0.8345 & -0.1372 & -0.0233 & -0.0569 \\
\hline & $\mathrm{N}(22)$ & -0.7303 & -0.7537 & -0.7588 & -0.0284 & -0.0233 & -0.0025 \\
\hline & $\mathrm{N}(23)$ & -0.6127 & -0.7917 & -0.7973 & -0.1845 & -0.1790 & -0.0027 \\
\hline \multirow[t]{17}{*}{ II } & $\mathrm{C}(1)$ & -0.1367 & -0.1657 & -0.1514 & 0.0143 & -0.0290 & 0.0071 \\
\hline & $C(2)$ & -0.0445 & -0.2058 & -0.1593 & 0.0464 & -0.1613 & 0.0232 \\
\hline & $C(3)$ & -0.1757 & -0.0181 & 0.1168 & 0.1350 & 0.1575 & 0.0675 \\
\hline & $C(4)$ & -0.3000 & 0.0411 & 0.1947 & 0.1536 & 0.3411 & 0.0768 \\
\hline & $C(5)$ & -0.2750 & -0.0633 & 0.1129 & 0.1763 & 0.2116 & 0.0881 \\
\hline & $C(6)$ & 0.3764 & 0.3877 & 0.3195 & -0.068 & 0.0113 & -0.0340 \\
\hline & $C(7)$ & -0.2497 & 0.0147 & 0.1322 & 0.1175 & 0.2644 & 0.0587 \\
\hline & $C(8)$ & 0.4521 & 0.3666 & 0.4060 & 0.0394 & -0.0855 & 0.01971 \\
\hline & $\mathrm{C}(9)$ & -0.1545 & 0.0217 & 0.1409 & 0.1192 & 0.1762 & 0.05960 \\
\hline & $C(10)$ & 0.2348 & 0.4330 & 0.5144 & 0.0813 & 0.1982 & 0.04068 \\
\hline & $\mathrm{O}(11)$ & -0.1581 & -0.1621 & -0.3797 & -0.2176 & -0.0039 & -0.10880 \\
\hline & $N(12)$ & -0.1403 & -0.2425 & -0.2691 & -0.0266 & -0.1022 & -0.01332 \\
\hline & $N(13)$ & -0.2064 & -0.2064 & -0.2657 & -0.0592 & -0.0065 & -0.02962 \\
\hline & $C(14)$ & -0.2348 & 0.0913 & 0.1712 & 0.0799 & 0.3261 & 0.03998 \\
\hline & $C(15)$ & -0.1782 & -0.0057 & 0.1041 & 0.10987 & 0.1725 & 0.05493 \\
\hline & $C(16)$ & 0.3017 & 0.3469 & 0.2782 & -0.0687 & 0.0452 & -0.03439 \\
\hline & $C(17)$ & -0.2365 & -0.0171 & 0.1134 & 0.1306 & 0.2194 & 0.06532 \\
\hline
\end{tabular}




\begin{tabular}{|c|c|c|c|c|c|c|c|}
\hline & $\mathrm{C}(18)$ & -0.2057 & -0.3585 & -0.2731 & 0.0854 & -0.1527 & 0.04271 \\
\hline & $C(19)$ & -0.2251 & 0.1036 & 0.1540 & 0.0503 & 0.3288 & 0.02517 \\
\hline & $C(20)$ & -0.7587 & -0.6904 & -0.3835 & 0.3068 & 0.0682 & 0.15342 \\
\hline & $C(21)$ & 1.0041 & 1.0159 & 0.9570 & -0.0589 & 0.0118 & -0.0294 \\
\hline & $\mathrm{O}(22)$ & -0.1243 & -0.2061 & -0.4171 & -0.2110 & -0.0818 & -0.10551 \\
\hline & $\mathrm{O}(23)$ & -0.1247 & -0.2807 & -0.4169 & -0.1361 & -0.1559 & -0.06809 \\
\hline \multirow[t]{22}{*}{ III } & $C(1)$ & -0.1068 & -0.2696 & -0.1914 & -0.0845 & -0.1627 & 0.03911 \\
\hline & $\mathrm{C}(2)$ & -0.0624 & -0.1127 & -0.0973 & -0.0348 & -0.0503 & 0.00772 \\
\hline & $C(3)$ & -0.1943 & 0.0639 & 0.1354 & 0.3298 & 0.2582 & 0.03577 \\
\hline & $C(4)$ & -0.2055 & 0.0712 & 0.1249 & 0.3304 & 0.2768 & 0.02682 \\
\hline & $C(5)$ & -0.2392 & -0.0478 & 0.0375 & 0.2768 & 0.1913 & 0.04271 \\
\hline & $C(6)$ & -0.2359 & -0.0650 & 0.0280 & 0.2640 & 0.1709 & 0.04654 \\
\hline & $C(7)$ & 0.3324 & 0.1988 & 0.3615 & 0.0291 & -0.1335 & 0.08133 \\
\hline & $C(8)$ & 0.4556 & 0.4128 & 0.4101 & -0.0454 & -0.0428 & -0.0013 \\
\hline & $C(9)$ & -0.2038 & -0.0707 & 0.1978 & 0.4017 & 0.1330 & 0.13433 \\
\hline & $C(10)$ & 0.2280 & 0.28550 & 0.2721 & 0.0440 & 0.0574 & -0.0067 \\
\hline & $\mathrm{O}(11)$ & -0.2368 & -0.3003 & -0.3297 & -0.0928 & -0.0634 & -0.0147 \\
\hline & $\mathrm{N}(12)$ & -0.1277 & -0.2212 & -0.3884 & -0.2606 & -0.0934 & -0.0836 \\
\hline & $\mathrm{N}(13)$ & -0.2319 & -0.1635 & -0.3110 & -0.0791 & 0.0683 & -0.0737 \\
\hline & $C(14)$ & 0.2423 & 0.1753 & 0.2487 & 0.0064 & -0.0669 & 0.03671 \\
\hline & $C(15)$ & -0.1870 & 0.0846 & 0.1707 & 0.3577 & 0.2716 & 0.04305 \\
\hline & $\mathrm{O}(16)$ & -0.4096 & -0.4077 & -0.6905 & -0.2809 & 0.0018 & -0.1413 \\
\hline & $\mathrm{O}(17)$ & -0.4178 & -0.4594 & -0.7053 & -0.2874 & -0.0416 & -0.1229 \\
\hline & $\mathrm{C}(18)$ & 0.4766 & 0.1048 & 0.3624 & -0.1141 & -0.3717 & 0.12880 \\
\hline & $C(19)$ & -0.2703 & 0.4500 & 0.8669 & 1.1372 & 0.7203 & 0.20844 \\
\hline & $C(20)$ & -0.2926 & -0.0204 & 0.1499 & 0.4426 & 0.2722 & 0.08521 \\
\hline & $C(21)$ & -0.2140 & -0.0078 & 0.0793 & 0.2934 & 0.2062 & 0.04359 \\
\hline & $C(22)$ & -0.2690 & -0.0305 & 0.0678 & 0.3368 & 0.2384 & 0.0491 \\
\hline \multirow[t]{14}{*}{ IV } & $C(1)$ & -0.1381 & -0.2445 & -0.1524 & -0.0143 & -0.1064 & 0.04605 \\
\hline & $C(2)$ & -0.0541 & -0.1674 & -0.1692 & -0.1151 & -0.1133 & -0.0009 \\
\hline & $C(3)$ & -0.1732 & -0.0125 & 0.0999 & 0.2731 & 0.1606 & 0.05626 \\
\hline & $C(4)$ & -0.2225 & 0.0597 & 0.1760 & 0.3985 & 0.2822 & 0.05818 \\
\hline & $C(5)$ & -0.2854 & -0.1075 & 0.0966 & 0.3820 & 0.1779 & 0.10207 \\
\hline & $C(6)$ & 0.3988 & 0.4199 & 0.3187 & -0.0800 & 0.0210 & -0.0505 \\
\hline & $C(7)$ & -0.2576 & -0.0453 & 0.1037 & 0.3614 & 0.2123 & 0.07454 \\
\hline & $C(8)$ & 0.4812 & 0.4070 & 0.4038 & -0.0774 & -0.0742 & -0.0016 \\
\hline & $\mathrm{C}(9)$ & -0.1607 & 0.0344 & 0.1221 & 0.2828 & 0.1952 & 0.04381 \\
\hline & $C(10)$ & 0.2305 & 0.3200 & 0.4008 & 0.1703 & 0.0894 & 0.04042 \\
\hline & $\mathrm{O}(11)$ & -0.7909 & -0.5119 & -0.6013 & 0.1895 & 0.2789 & -0.0446 \\
\hline & $\mathrm{N}(12)$ & -0.3701 & -0.4090 & -0.4506 & -0.0804 & -0.0389 & -0.0207 \\
\hline & $\mathrm{N}(13)$ & -0.4791 & -0.6525 & -0.6730 & -0.1939 & -0.1733 & -0.0102 \\
\hline & $C(14)$ & 0.4543 & 0.06920 & 0.4082 & -0.0461 & -0.3851 & 0.16950 \\
\hline
\end{tabular}


ISSN 2321-807X

\begin{tabular}{lllllll}
\hline $\mathrm{C}(15)$ & 0.2383 & 0.14382 & 0.2856 & 0.0473 & -0.0945 & 0.07092 \\
$\mathrm{O}(16)$ & -0.6488 & -0.6866 & -0.6975 & -0.0487 & -0.0377 & -0.0054 \\
$\mathrm{C}(17)$ & -0.1913 & 0.0811 & 0.2894 & 0.4808 & 0.2724 & 0.10418 \\
$\mathrm{C}(18)$ & -0.2619 & -0.0148 & 0.0260 & 0.2879 & 0.2470 & 0.02042 \\
$\mathrm{C}(19)$ & -0.2774 & -0.0187 & 0.1992 & 0.4766 & 0.2587 & 0.10899 \\
$\mathrm{C}(20)$ & -0.2164 & -0.0191 & 0.2341 & 0.4506 & 0.1973 & 0.12663 \\
$\mathrm{O}(21)$ & -0.5367 & -0.6704 & -0.9123 & -0.3755 & -0.1337 & -0.12092 \\
$\mathrm{C}(22)$ & -0.2750 & 0.4556 & 0.3919 & 0.6669 & 0.7306 & -0.03186 \\
\hline
\end{tabular}

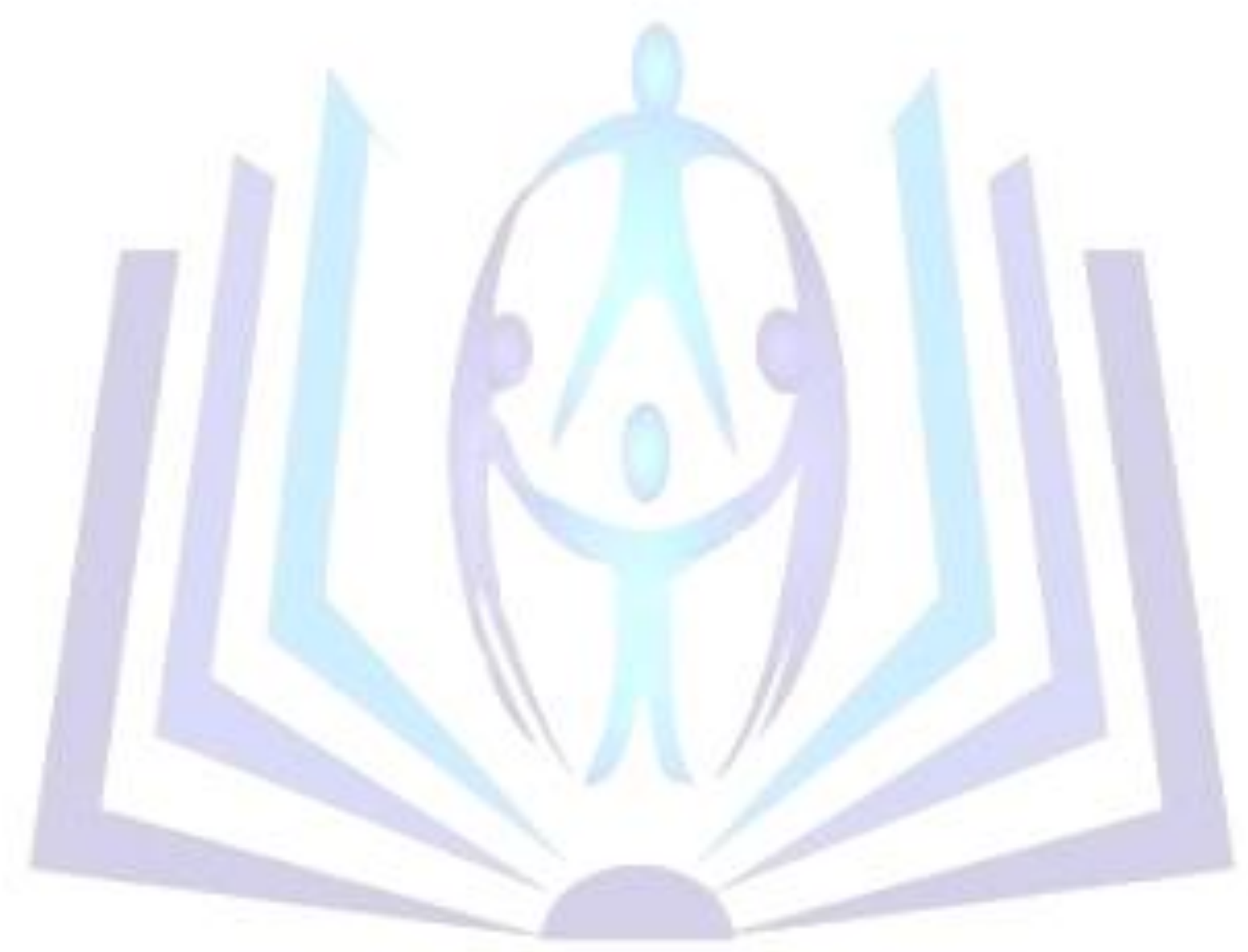

